\title{
Colonización, baldíos y colonos, el caso de Carare, Santander, Colombia 1953-1957.'
}

Olga Marina García Norato ${ }^{2}$

\begin{abstract}
Resumen
Las estrategias planteadas por el gobierno del General Gustavo Rojas Pinilla de 1953 a 1957, para lograr los objetivos del programa de colonización dirigida en el Carare - Santander - Colombia, tales como: Plan Vial, Colonización e Industrialización, pretendían vincular la región a la economía nacional e internacional, con el fin de brindar a los colonos, mejores condiciones de vida, mediante la dotación de infraestructura productiva: vías, aeródromo, maquinaria, titulación de baldíos, créditos, seguro contra riesgos de pérdida o deterioro a que estaban expuestos los productos de la agricultura y la ganadería y dotación de infraestructura reproductiva como: construcció de puesto de higiene, escuelas, vivienda, hotel, iglesia y bases militares. Estas orientaciones contribuyeron no solo a pacificar la región sino también a brindar las posibilidades económicas y sociales para los colonos, lo cual permitió el incremento poblacional a tal punto que poblaciones como Cimitarra, Landázuri, Puerto Parra y Santa Helena del Opó, fueran erigidas como municipios en la década siguiente.
\end{abstract}

Palabras clave: colonización, economía, condiciones de vida, infraestructura.

\footnotetext{
1. Este artículo es producto de la tesis doctoral titulada Colonización Carare Santander Colombia 1953-1957 elaborada en la Línea en Historia Social y Económica del Doctorado en Historia de la UPTC.

2. Economista, Esp. Finanzas, Magister en Desarrollo Rural y Candidata a doctora en Historia. Universidad Pedagógica y Tecnológica de Colombia, Edificio administrativo, $5^{\circ}$ Piso, Of. Vicerrectoría Académica, Avenida Central del Norte, Tunja, Boyacá, Colombia. Investigadora del Grupo de Investigación: Educación y Desarrollo Rural. UPTC. E-mail: olgarcia06@yahoo.es
} 


\title{
Colonization, waste land and settlers the case of Carare Santander Colombia 1953-1957
}

\begin{abstract}
Strategies enforced by General Gustavo Rojas Pinilla's government between 1953-1957, to achieve the goals of the oriented settling program in the village of Carare, in Santander, Colombia, such as a road plan, colonization and industrialization. Those plans intended to link the region to national and international economy, aiming to provide settlers with better living conditions, through the endowment of productive infrastructure: roads, an airfield, machinery, waste land entitlement, loans, loss or damage risk insurance for agricultural and livestock products, and reproductive infrastructure allocation, such as: building a sanitary station, schools, housing, hotel, church and military bases. Such guidelines contributed not only to bring peace to the region, but also to allow for economic and social possibilities for settlers, which in turn allowed for population increase to the extent that villages like Cimitarra, Landázuri, Puerto Parra and Santa Helena de Opón were erected as municipalities in the next decade.
\end{abstract}

Key words: colonization, economy, living conditions, infrastructure.

Recibido: 17 de mayo 2012 Aceptado: 19 de octubre 2012

\section{Introducción}

Para abordar la tipología institucional de los procesos de colonización en Colombia en el siglo XX, fue necesario caracterizar los tipos de colonización, desde diferentes autores y especialmente el planteamiento hecho por la política pública sectorial, orientada por el General Gustavo Rojas Pinilla en su periodo de gobierno, temática en la cual se centra el interés de éste artículo, en aras de identificar los programas que se ejecutaron y el impacto económico y social generado en la región del Carare - Santander - Colombia.

Se identificaron y analizaron fuentes documentales históricas de 1953-1957 tales como: Decretos, Actas, Escrituras de titulación de baldíos a colonos espontáneos y dirigidos del archivo histórico del Instituto Colombiano de 
Desarrollo Rural INCODER, y otros archivos como: Archivo General de la Nación, Archivo del Congreso de la República, Archivo del Ministerio de Agricultura, Biblioteca Nacional, Biblioteca de la Universidad Industrial de Santander, Biblioteca Luis Ángel Arango, Archivo de la Oficina de Registro de Instrumentos Públicos de Vélez Santander Colombia, IGAC, Periódicos: Vanguardia Liberal, El Tiempo, El Deber. Revistas de Economía Colombiana, Revista Nacional de Agricultura. Igualmente se obtuvo información por medio de visitas a la región objeto de estudio e historiografía sobre el tema de colonización.

\section{Ubicación Geográfica, región del Carare-Santander- Colombia}

La región del Carare está localizada en la zona suroccidental del departamento de Santander. Este se encuentra localizado en el noreste de Colombia, tal como se aprecia de color rojo en el mapa Figura 1. Es uno de los departamentos más montañosos del país, posee una amplia zona plana y baja. Se distinguen dos grandes unidades fisiográficas: 1. El valle del Magdalena y 2. La cordillera Oriental.

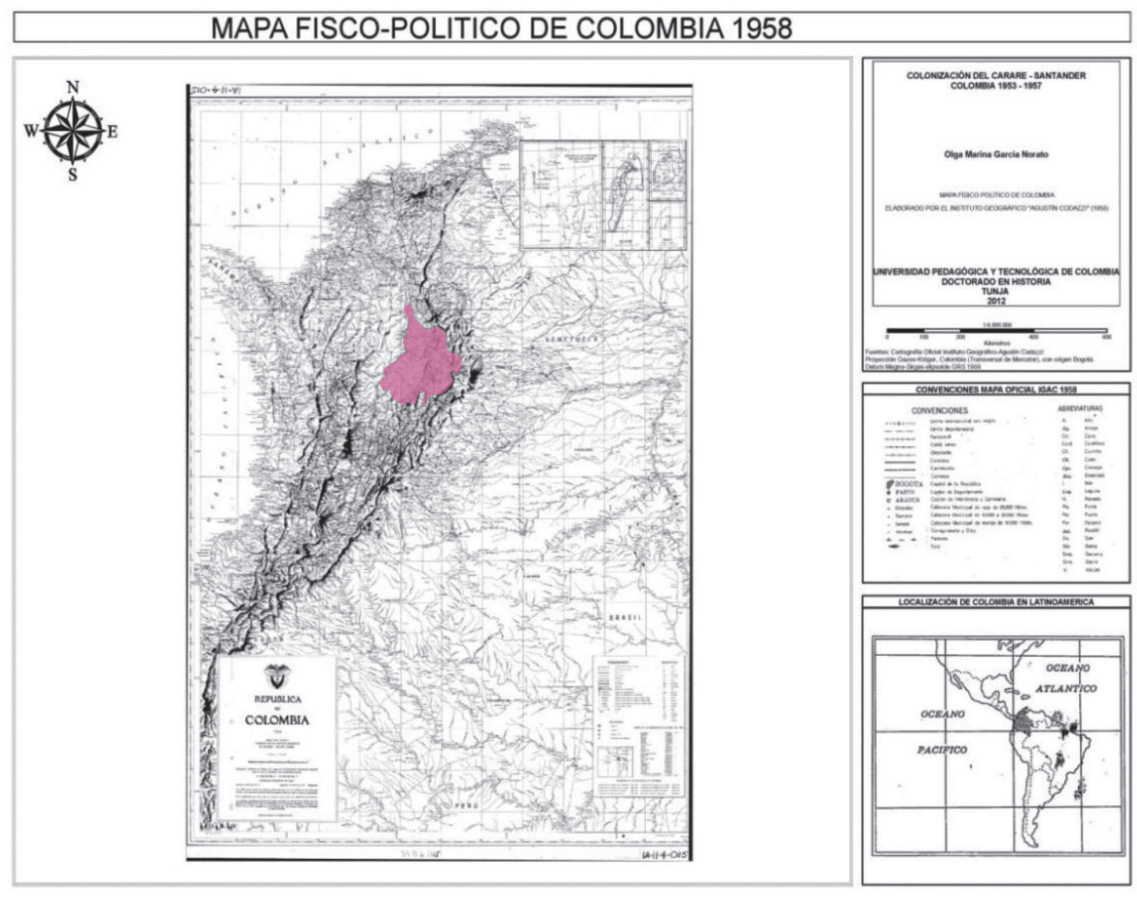

Figura 1. Cartografía oficial Instituto Geográfico Agustín Codazzi. Proyección Gauss - Kruger, Colombia (Transversal de Mercator), con origen Bogotá, 1980, escala 1:6.000.000 


\section{El Valle del Magdalena}

El Valle del Magdalena medio se encuentra ubicado en la mitad occidental del Departamento de Santander, se caracteriza por la topografía plana y suavemente ondulada, "con predominio de acumulaciones fluviales del cuaternario y rocas sedimentarias del terciario. La lluvia es del orden del 2.500-3.000 mm anuales, con leve incremento en los alrededores de Barrancabermeja", (Instituto Geográfico Agustín Codazzi IGAC, 1992). En la parte occidental sobre la ribera del río Magdalena, predomina la vegetación selvática y hacia el centro oriente, el bosque ecuatorial, ambos tipos de vegetación del piso bioclimático cálido, los suelos son pobres en bases, aptos para las actividades ganaderas.

\section{La cordillera oriental}

La cordillera oriental recorre el costado oriental del departamento en dirección general suroeste-noreste. Según el IGAC, es de topografía quebrada y abrupta, con alturas superiores a $3.000 \mathrm{~mm}$, en la cordillera de los Yariguíes divisoria fluvial, rio Suarez al oriente y rio Magdalena al occidente; las lluvias en la mayor parte de la cordillera son de $1.500-2.000 \mathrm{~mm}$. (Instituto Geográfico Agustín Codazzi IGAC 1992). La vegetación corresponde a los pisos bioclimáticos templado y fríos. Los suelos, desarrollados en laderas, son pobres en bases aptos para uso agrícola selectivo y para cobertura vegetal.

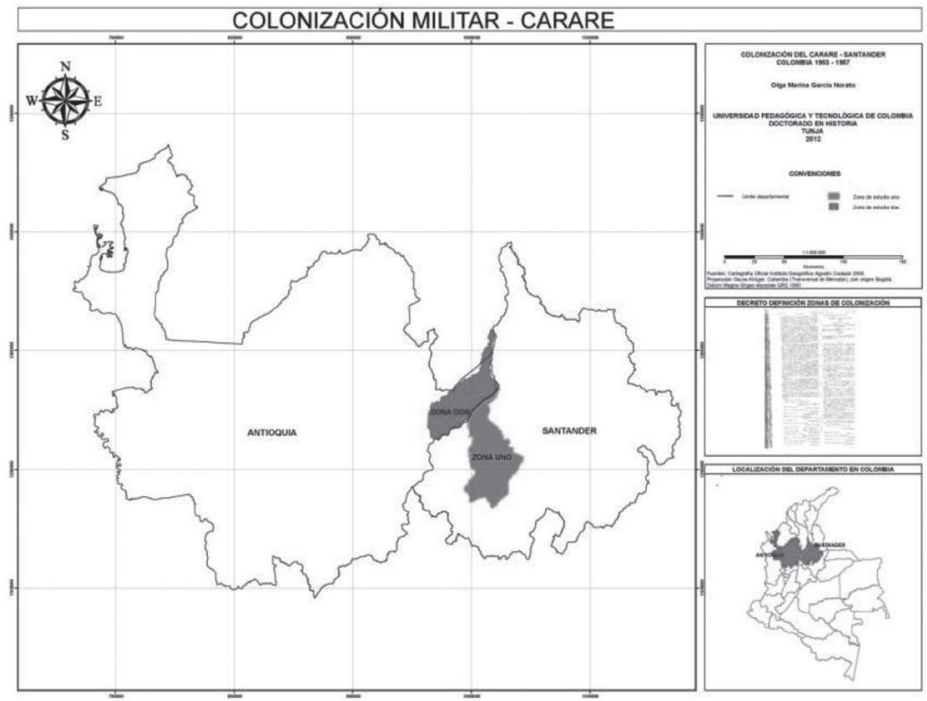

Figura 2. Elaboración de la autora, con base en el Decreto No. 870 del 26 de marzo de 1953, ubicación en la Cartografía oficial del IGAC 2008. Proyección Gauss. Kruger, (Transversal de Mercator), origen. Bogotá. Dantum. Magna- Sirgas Elipsoide GRS 1980” Tunja, agosto de 2012. 
A partir del decreto 0870, expedido el 26 de marzo de 1953, firmado por el designado Presidente Roberto Urdaneta Arbeláez, quien reemplazaba temporalmente al Presidente Laureano Gómez dos meses y medio antes de asumir como presidente de la República de Colombia el General Gustavo Rojas Pinilla, quien era el comandante de las Fuerzas Armadas de Colombia, se asignan dos zonas de colonización militar en el valle del río Magdalena.

La institución que asumía para entonces la responsabilidad social y económica de la colonización, era el Instituto de Parcelaciones, Colonización y Defensa Forestal, el cual, en coordinación con los Ministerios de Guerra, Agricultura, Higiene y Obras Públicas, Instituto de Crédito Territorial, Caja de crédito Agrario Industrial y Minero, debían orientar con destino a los miembros de las Fuerzas Armadas en servicio activo y retirados, las zonas de terrenos baldíos ubicadas en el Valle del río Magdalena, las cuales se encontraban ubicadas en los departamentos de Santander y Antioquia.

\section{Primera zona}

Ubicada en el departamento de Santander, demarcada con color verde en la Figura 2, cuya ubicación corresponde a la cartografía oficial del Instituto Geográfico Agustín Codazzi. De acuerdo con el decreto mencionado, está delimitada de la siguiente manera: partiendo de la desembocadura del río Carare, en el río Magdalena, se sigue aguas abajo por éste hasta encontrar la desembocadura del río Opón, en el brazo Opón; de este punto aguas arriba hasta encontrar la desembocadura de la quebrada negra de Armas, en este río; se sigue por la quebrada Negra de Armas aguas arriba hasta su nacimiento; de aquí en línea recta al suroeste hasta encontrar el río Horta, cerca al lugar denominado Rancho Grande; siguiendo por el río Horta Aguas abajo hasta su desembocadura del río Carare o Minero; de este sitio aguas abajo del río Carare hasta su desembocadura en el río Magdalena, punto de partida, (Presidencia de la Republica, 1953).

Cabe resaltar que la delimitación anterior se utilizó para ubicar la región del Carare, en la cual se realizó el programa de colonización orientado por el General Gustavo Rojas Pinilla en el periodo 1953-1957, quien asumió funciones presidenciales el 13 de junio de 1953; en el mes de julio del mismo año, creó el Instituto de Colonización e Inmigración en reemplazo del Instituto de Parcelaciones Colonización y Defensa Forestal, como la nueva institucionalidad que asumió el liderazgo en la coordinación del programa de colonización de la zona No. 1 del Carare - Santander - Colombia, la cual fue objeto de ésta investigación.

Antes de presentar el contenido programático de la colonización del Carare, es importante conceptualizar y caracterizar los diferentes tipos de colonización vistos desde diferentes categorías de análisis en la historiografía colombiana. 


\section{Colonización}

Diferentes autores de la historiografía económica colombiana, que han estudiado acerca de la colonización de las selvas y llanuras, manifiestan que éste tema tiende a convertirse en un área especializada de lo que podría llamarse las sociologías de la colonización ${ }^{3}$, las cuales muestran con alguna especificidad de acuerdo con las regiones estudiadas, planteamientos y orientaciones de políticas públicas, por medio de diferentes programas, casi siempre con apoyos económicos tales como: créditos, titulación de baldíos y planificación de cultivos entre otros; igualmente en el tema social ofrecen soportes desde la institucionalidad de gobierno tales como: creación de escuelas, centros de higiene, vivienda rural y urbana y escenarios deportivos entre otros; en infraestructura apoyan con recursos para la construcción de vías, ferrocarriles, telégrafos, casas campesinas, parques y edificios municipales.

Para el caso colombiano, cabe resaltar la configuración de algunas peculiaridades que se deben destacar desde ahora como: el ciclo migración - colonización conflicto - migración, que traslada a muchos de sus actores, incluso, por medio del tiempo y el espacio, como elementos constantes en el proceso de la colonización y que junto a ellos lleva y reproduce las estructuras agrarias y las contradicciones propias de ellas, prácticamente a todos los rincones de la frontera agrícola, pero también se va haciendo visible en esta historia según Darío Fajardo: " $L a$ presencia de la organización de los colonos, fenómeno que en cierta medida rompe con la tradición, prácticamente universal del individualismo como rasgo de las sociedades de frontera", (Fajardo, 2012).

A continuación se describen los tipos de colonización, tanto espontáneos como dirigidos, desde diferentes visiones y conceptos de la historiografía colombiana.

\section{Colonización espontánea}

Se da como consecuencia de las imprevisiones del gobierno, que a pesar de que ha intentado apoyar la aspiración de los colonos de tener un pedazo de tierra vía reforma agraria y regulación que ampare la posesión de la misma durante un periodo de tiempo, no lo ha logrado. El colono se desplaza por su propia iniciativa a las zonas inexplotadas, sin más apoyo que sus elementales conocimientos agrícolas, tratando de conseguir una superficie de tierra cuya 
extensión y productividad, dependerá única y exclusivamente de la capacidad laboral familiar. Según Artunduaga: "Con la esperanza de que el valor de su trabajo representado en su parcela lo coloque dentro de las formas de crédito con que se premia su esfuerzo" (Artunduaga, 1978).

Al considerar estos programas, es necesario realizar un estudio escrupuloso de las conveniencias, por ejemplo: se puede comparar el valor de la producción que se espera obtener como resultado de la colonización del área y la probabilidad de causar degradación ambiental, con el valor que se podría obtener dejando la región inhabitable, protegiendo las cuencas contra erosión y disfrutando de los beneficios de la cobertura vegetal, y el control y la calidad del agua.

\section{Colonización Dirigida}

En Colombia, la ocupación del territorio no ha constituido un proyecto estatal de largo plazo, ni una estrategia geopolítica definida; ha sido un proceso resultante de formas de apropiación privadas del territorio, en las que incidieron los ciclos del comercio exterior de materias primas agropecuarias, y la dinámica de la economía nacional.

La política agraria, de alguna manera estimuló directa o indirectamente la expansión de la frontera, sin suficiente atención estatal, en lugar de buscar una mejor distribución de los recursos al interior de la frontera, para evitar la gran destrucción de recursos que ha significado la colonización, la inmensa generación de conflictos, la irracional explotación del suelo y la gestación de movimientos y protestas contra el Estado.

La colonización dirigida se enmarca como una política pública planificada, que busca aglutinar diversos intereses, objetivos y visiones de desarrollo económico, social, cultural y de infraestructura, para la población que no tiene la posibilidad de acceder a la tierra, con el propósito de que en ella se produzcan bienes para su subsistencia y la de su familia, pues esta población además de ser numerosa, se caracteriza por tener baja o nula posibilidad de empleo y bajos ingresos. En éste orden de ideas algunos autores la describen de la siguiente manera:

"Los antecedentes sobre la tenencia y el mercado de tierras en Colombia, se pueden circunscribir a dos grandes aspectos: el intento de poner tributos progresivos a la propiedad rural, y la reforma agraria. Ambos procesos han fracasado en movilizar la tierra como factor productivo y en constituir un verdadero mercado de tierras con elementos económicos de formación de precios y dinamización de la oferta y la demanda. También fracasaron en crear elementos para corregir la desigualdad en la apropiación de la tierra reflejada en una estructura agraria bimodal", (Johnston 1980). 
Lauchlin Currie sugería en su análisis incrementar la productividad agrícola a partir de la tecnificación, lo cual podría beneficiar a la nación siempre y cuando se anunciaran oportunidades de empleo para la población rural desplazada. Currie afirmaba por un lado que:

"Ignorar éste dilema y llevar a cabo reforma agraria, construcción de carreteras de penetración, grandes proyectos de recuperación de tierras y mejorar las facilidades de crédito, todas medidas tendientes a mejorar la producción, en la medida que fomentaran la competencia y bajaran los ingresos medios rurales, sería una política cruel, injusta y sumamente peligrosa", (Currie, 1976).

Junto a lo anterior, la colonización dirigida se establece como un programa de gobierno que, por medio de un estudio socio-económico previo, busca dotar de tierras propias al campesino que va siendo desplazado por su índice demográfico y otros factores ya enunciados. Gustavo Artunduaga Paredes, por su labor en el proceso de colonización dirigida en la región de Caquetá - Colombia, a mediados del siglo XX, destaca el tema de la planificación de los programas de colonización dirigida, a través de organismos especializados a partir de un proyecto, el cual debía contemplar los siguientes aspectos: Estudios preliminares del área que se escoja y delimitación de su superficie; situación geográfica, topográfica e hidrográfica; análisis de suelos; climas; superficie de la unidad familiar (parcela) (Artunduaga, 1978).

Katherine LeGrand parte de una crítica a la visión tradicional que hay sobre el campesinado en América Latina, describe cómo a éste se le ha considerado como un personaje pasivo frente a las relaciones económicas y políticas, construidas en torno a la tierra y al desarrollo de la agricultura. Su análisis se centra en los conflictos agrarios generados en Colombia, como resultado de la concentración de la propiedad, concentración producida por las políticas de distribución de tierras y titulación de baldíos (LeGrand, 1989).

LeGrand examina, como antecedentes de los conflictos agrarios, las relaciones entre la distribución de la población en el territorio colombiano y las posibilidades de explotación de la tierra, las políticas sobre asignación de las tierras baldías, las relaciones de poder entre los grandes beneficiarios de las concesiones de tierras y las colonizaciones, como resultado de la concentración de la propiedad territorial. El texto analiza el marco político nacional en el que se dieron estos conflictos, su desarrollo posterior en la violencia de los años 50 como antecedente de la ley 135 de 1961 y las limitaciones para su aplicación (LeGrand, 1989).

Respecto al tema de la colonización dirigida, establece dos modalidades principales: la primera orientada a la fundación de nuevos centros de población, pretende ensanchar la frontera, mediante el asentamiento de gentes en lugares que con el tiempo se convirtieron en nuevos distritos; para esto se concederían tierras 
a los nuevos ocupantes, y aunque se dijo que terminó hacia finales del XIX (LeGrand 1989), el proceso ha continuado.

Desde otra perspectiva Donny Meertens establece la colonización dirigida, como un proyecto de gobierno, a una parte de la población urbana que había sido desplazada por la violencia y se encontraba ubicada en los cinturones de miseria de las grandes ciudades (Meertens, 1998).

A mediados de la década de 1940 y a principios de 1960, ocurrieron importantes migraciones internas en el país, relacionadas con la guerra civil y los cambios en la economía que condujeron a una rápida urbanización de la población y a la apertura de nuevos frentes de colonización; cabe mencionar aquí la colonización dirigida por el General Gustavo Rojas Pinilla en el período de gobierno $1953-1957$.

Colonización dirigida empresarial: "Centros de colonización”, del General Gustavo Rojas Pinilla

El gobierno del General Gustavo Rojas Pinilla 1953-1957, orientó en Colombia una política de colonización dirigida que pretendía: "Fomentar el progreso económico y social de las partes menos desarrolladas del país, a través de centros de colonización y de una política de estímulo a la inmigración”, (Presidencia de la República, 1953), para lo cual era necesario reorganizar las funciones del Instituto de Parcelaciones, responsable del tema de colonos, hasta antes de iniciar su gobierno.

Es por ello que crea el Instituto de Colonización e Inmigración mediante el decreto 1894 de julio 18 de 1953, con el fin de coordinar acciones encaminadas a incorporar algunas regiones del país, con alto potencial productivo, a la economía nacional, tales como: Ariari, Orinoquía, Sarare, Patía, Baudó y Carare. Este instituto debía garantizar, a partir de la coordinación interinstitucional, el acceso a la tierra, crédito, posibilidades de empleo, ingresos, infraestructura productiva - económica y reproductiva - social, entre otros aspectos, condiciones de vida dignas hacia los colonos inmigrantes nacionales y extranjeros.

Para lograr este propósito, debía igualmente ubicar a los colonos en las regiones identificadas por el gobierno con mayores y mejores potencialidades productivas, teniendo en cuenta su ubicación geográfica, vías, clima, recursos hídricos y facilidad de acceso a puertos, que permitieran el comercio nacional e internacional de la producción obtenida a partir del trabajo de los colonos que se ubicaran en dichas zonas.

Los inmigrantes de distintas regiones de Colombia que se trasladan a colonizar el hoy llamado núcleo provincial del Carare - Opón, con sede en Cimitarra, provenían de tierras frías, especialmente del altiplano cundiboyacense, de Antioquia, del 
Tolima y de otras regiones del país, los cuales debían acomodarse en una tierra cálida sin explotar, con necesidades básicas de infraestructura vial, de servicios de educación, salud, maquinaria y de capital para desarrollar el trabajo de explotación maderera y adaptarse a las nuevas exigencias de la región colonizada.

\section{Vinculación de colonos a la economía nacional e internacional}

El diario más importante del departamento de Santander, Vanguardia Liberal, refiriéndose al interés del gobierno del General Rojas Pinilla registra lo siguiente:

"50.000 Hectáreas para la Cooperativa Colonial del Carare. Que el gobierno destine un área de 50.000 hectáreas con destino a los socios de la Cooperativa Colonial del Carare, para el desarrollo de las labores agrícolas, en la mitad de la selva y 100 hectáreas para la construcción de casas, para los cooperados, al igual que para servicios, construcción de escuelas, iglesia, centro de higiene y oficinas públicas", (Vanguardia Liberal, 1954).

Para los colonos significaba, en términos económicos, tener la posibilidad de acceder a la tierra, como factor de producción y generación de ingresos, pero sobre todo para el gobierno, cumplir con el proyecto político del General, vinculando las tierras productivas adjudicadas a la economía nacional para generar mayores cifras de crecimiento económico al país, como una alternativa de superar las difíciles condiciones de atraso y de pobreza de la población colombiana.

¿Cuántos colonos llegaron al Carare?

La población del departamento de Santander en 1951 era de 748.000 habitantes equivalentes a $6.5 \%$ de la población del país, ubicada en una superficie de 32.000 $\mathrm{Km} .^{2}$, la cual corresponde al 2.8 de la superficie total de Colombia y con una densidad poblacional de 23.4 habitantes por Km. ${ }^{2}$. El censo de 1964, arroja una población en el departamento de Santander de 1.001.213; el incremento de población, respecto al anterior censo de 1951 fue de 253.507 habitantes en el departamento de Santander, es decir un incremento porcentual de 22.39. En el periodo comprendido entre los años de 1953 y 1956, el instituto distribuyó 65.000 hectáreas de tierra entre 3.260 familias campesinas, (ONU, 1956).

Primera estrategia de desarrollo económico: Infraestructura.

Plan vial.

Para el caso que nos ocupa, tomando como referente las ejecutorias en la región de colonización del Carare-Opón, en el cual el gobierno nacional, por intermedio del Instituto de Colonización e Inmigración (ICI) y con la 
colaboración del Ministerio de Obras Públicas, construyó cuatro grandes rutas de penetración, primera: la antigua carretera Barbosa Vélez Jordán; Segunda: la nueva hacia la Mugrosa. Tercera: la nueva hacia el Nare y Cuarta: la nueva hacia el Aeródromo. Las tres primeras son obra del ICI; la primera ha sido mejorada por el ICI con obras de mantenimiento (Revista de Economía Colombiana, 1954).

Lo expuesto en la revista de economía colombiana, coincide con lo publicado en el diario Vanguardia Liberal: "La única comunicación era un camino de herradura Barbosa, Vélez, el Jordán, por lo tanto se orientan recursos para continuar los trabajos de construcción de la carretera Vélez, Jordán, Landázuri, Cimitarra, Puerto Araujo”, (Revista de Economía Colombiana, 1954). Éste periódico resaltaba igualmente la importancia de continuar la construcción del ferrocarril la cual había empezado en 1922, quedando paralizada en el municipio de Barbosa, el cual debía conectarse con Barrancabermeja atravesando la zona de colonización.

\section{Aeródromo.}

En desarrollo del plan de colonización se construyó en el Carare un Aeródromo, en la población de Cimitarra, con todas las especificaciones técnicas exigidas por la Aeronáutica Civil, para el servicio de aviones DC3, figura 3.

El aeródromo lo construyó el Instituto de Colonización e Inmigración ICI y: "los gastos le serán reembolsados por la Corporación de Aeródromos Nacionales en cuanto estén terminadas las obras complementarias: radio faro, torre de control, zona de parqueadero y hotel”, (Revista de Economía Colombiana, 1954).

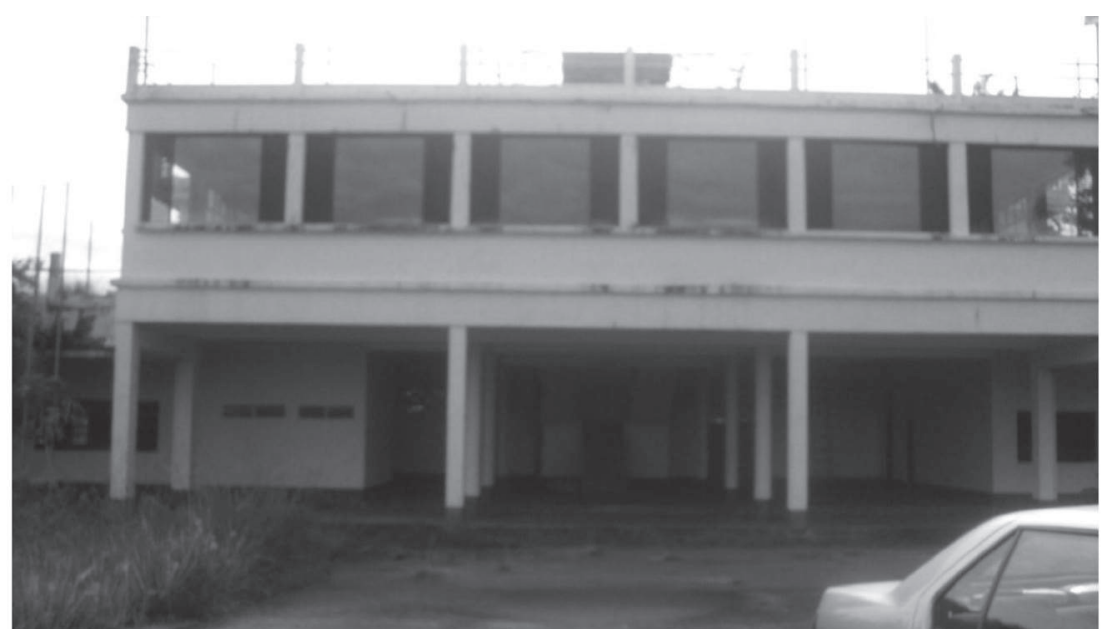

Figura 3. Aeropuerto de Cimitarra Gustavo Rojas Pinilla Fuente: Autora, tomada en mayo 4 de 2012. 
El aeropuerto Gustavo Rojas Pinilla de Cimitarra, se construyó e inauguró el 21 de junio de 1954, con el fin de que los comerciantes, funcionarios públicos y extranjeros pudieran llegar a la región y de ésta manera lograr vincular la producción del Carare a la economía nacional e internacional, como propósito fundamental del programa de colonización del general Rojas Pinilla.

\section{Segunda estrategia de desarrollo económico: colonización}

La segunda estrategia de desarrollo económico es la colonización, la cual se interpreta en el presente artículo, teniendo en cuenta las orientaciones de la política pública institucional, que estableció el General Rojas Pinilla en el periodo 1953-1957, en el Carare. Se puede evidenciar en la comunicación que Augusto Espinosa Valderrama publica en Vanguardia Liberal así: "En tierras del Carare, se disponen de todos los elementos para una explotación, en forma casi por el sistema norteamericano, en abundancia y pueden empezar a adquirir comodidades, igualmente describe el estado de las obras que se realizaban en 1954 tales como: habitaciones para el alto personal directivo ya están siendo satisfactorias, están mejorando el casino y se encuentran preocupados por alojar bien a todos los trabajadores”, (Espinosa Valderrama, 1954).

El presidente Rojas Pinilla orientó un programa para colonos, considerado por los más destacados líderes del departamento de Santander como el más importante del país, lo cual se evidenció en el registro que hizo la prensa escrita que para la época era Vanguardia Liberal, en su titular del 2 de junio de 1954:

"Reunión extraordinaria del Comité de Acción Santandereano hoy, conferencia de Mario Silva en los salones del Club del comercio, se realiza a las 5:30, para explicar la experiencia del viaje a Cimitarra, donde el gobierno nacional hace el proyecto de colonización más importante del país, dada la fertilidad de la tierra y por tanto de mayor porvenir en la economía nacional”, (Vanguardia Liberal 1954).

La dotación de infraestructura productiva y reproductiva adelantada en el período 1953 a 1957 en la población de Cimitarra, permitió incorporar la región del carare a la economía nacional, para darle auge a la zona que a través de la historia se debía convertir en una de las regiones más importantes del país, teniendo en cuenta su riqueza económica basada en la explotación maderera, minera y ganadera de nivel empresarial, para la autosuficiencia de la región poseedora de grandes posibilidades de generación de excedentes.

\section{Vivienda para colonos}

El 12 de mayo de 1954 el diario santandereano con el titular: "Situación actual de las fértiles tierras del Carare”, la describe de la siguiente manera: 
"El caserio de Cimitarra está situado a la pura orilla del río Guayabito y de la carretera del Carare, a 100 kilómetros de Vélez y 64 de Puerto Olaya”, las antiguas viviendas están construidas en tablas y palmas, hay 10 casas construidas por el Instituto de Crédito Territorial, de materiales sólidos y estilo moderno, (Vanguardia Liberal, 1954). La figura 4, tomada en mayo de 2012, permite observar una casa del municipio de Cimitarra, la cual fue construida en 1954 como lo registra el Diario Vanguardia Liberal.

En la visita realizada a éste municipio, el señor Alfredo García, residente desde hace 35 años en el municipio de Cimitarra, nos informó donde estaban ubicadas las primeras casas que se construyeron allí por el Instituto de Crédito Territorial INSCREDIAL, y se logró hacer ésta fotografía.

De igual manera Espinosa Valderrama ${ }^{4}$ establece, que a los colonos que llegaron a la región, les dieron granjas, en las cuales se construyeron viviendas con apoyo institucional, se encuentra en Vanguardia Liberal: "Concluirán 20 casas construidas por el Instituto de Crédito Territorial, cada casa tendrá 20 hectáreas adjudicadas, se entregarán con plantaciones hechas por el Instituto de Colonización e Inmigración, con ganado, caballos, mulas y vacas de leche”, (Vanguardia Liberal, 1954).

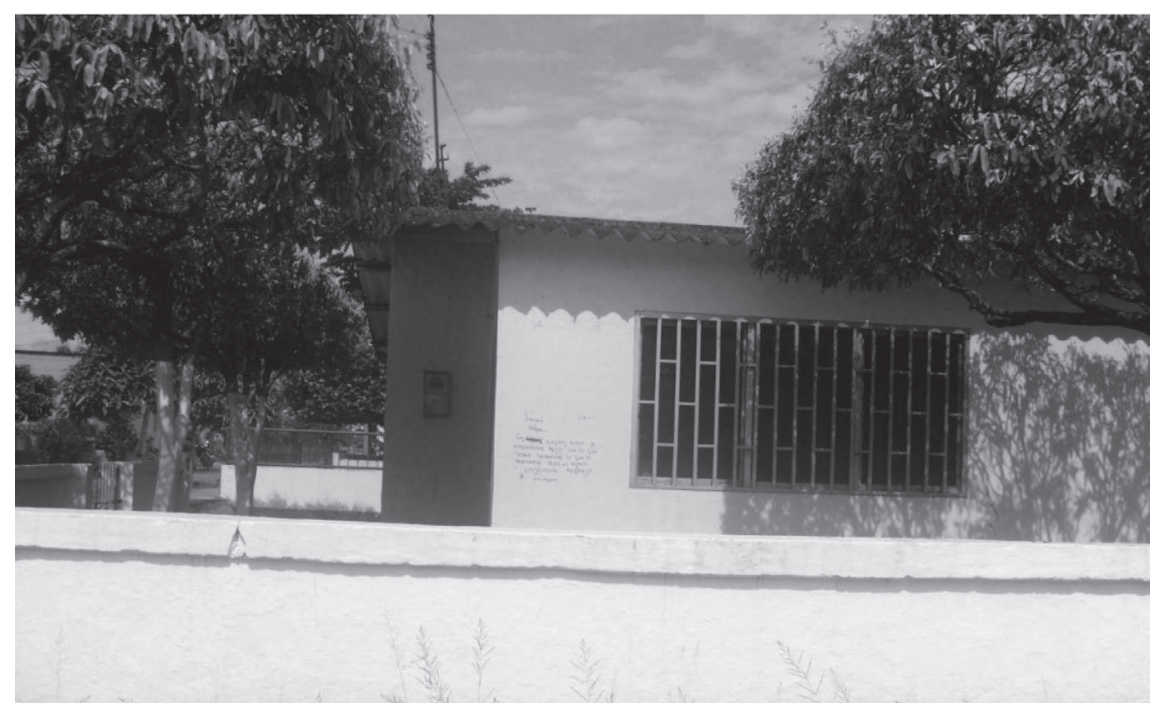

Figura 4. Vivienda de colono construida en Cimitarra en 1954 con el apoyo del Instituto de Crédito Territorial. Fuente: Autora, tomada el 4 de mayo de 2012.

4. Abdón Espinosa Valderrama, líder del partido liberal en el departamento de Santander- Colombia, fue Ministro de Estado y Parlamentario por este departamento. 


\section{Crédito para colonos}

El gobierno colombiano apoyó la política pública de desarrollo económico con una estrategia muy importante, a partir del fortalecimiento a colonos con créditos que les permitieran acceder a la tierra y a los factores de producción que se requerían, para generar una mayor productividad en el Carare; ésta estrategia, al igual que la de dotación de infraestructura vial y de servicios, apuntaba a cumplir con el objetivo planteado inicialmente de incorporar la región a la economía nacional.

Los colonos de la región contaron con la financiación, a plazos adecuados, facilitada por el ICI directamente o por intermedio de las entidades nacionales tales como: Instituto de Crédito territorial, Caja de Crédito Agrario, Fondo de Fomento Ganadero y Banco Popular, para la adquisición de sus tierras, construcción de viviendas, compra de herramientas, semillas, ganados y demás gastos de explotación y sostenimiento (Vanguardia Liberal, 1954).

El apoyo orientado por el gobierno a los colonos santandereanos, como estímulo al compromiso con los que trabajaran en las empresas de explotación maderera que se establecieron en Cimitarra, hacía referencia a crédito y a un derecho que les permitiera acceder a 200 hectáreas adicionales, puesto que se dejaron reservas para tal fin, de tierras buenas en la margen del río Guayabito afluente del Carare, a 80 kilómetros de Puerto Olaya y 100 kilómetros de Barbosa. Por este medio evitarían que santandereanos perdieran sus mejores tierras.

En aras de apoyar a los colonos para la compra de parcelas y apoyo a la producción, el gobierno abrió una oficina del Banco Popular Colonial, la cual fue inaugurada en Cimitarra con un capital de: "Cinco millones de pesos, con destino a crédito para colonos, para incremento de ganadería $y$ explotación de maderas. En esta misma fecha, serán entregados a los colonos de Cimitarra 196 cabezas de ganado entre vacuno y caballar, además titulación para 2.000 colonos", (Vanguardia Liberal, 1955). Esta cifra con destino a crédito para colonos, era muy significativa, y permite evidenciar que la región si se benefició económicamente.

Así las cosas, es importante resaltar que el informe que entregó el gerente del ICI, al señor Presidente de la República de Colombia, General Rojas Pinilla, una vez se liquida dicha institución, para que asuma sus funciones la Caja de Crédito Agrario el 2 de marzo de 1956, describe cómo se realizó el proceso de colonización del Carare, lo cual nos permite evidenciar la importante presencia institucional, con el propósito de dotar la región de infraestructura que le permitió vincularla a la economía nacional e internacional.

En los siguientes términos presentó el informe el gerente liquidador del ICI: "Dicha colonización se inició en forma espontánea, el ICI constituyó en la 
población de Cimitarra un centro que contaba con los siguientes servicios: iglesia, casino, cuarteles para puesto militar, comisariato, puesto de salud, servicios de correos, telégrafos y teléfono, escuela, urbanización, alumbrado y energía eléctrica", (Caballero Calderón, 1953). Se evidencia que en los 31 meses que el ICI ejerció las funciones de coordinación del programa de colonización, instaló en ésta región una infraestructura de dotación de servicios básicos, para generar bienestar a los colonos.

\section{Colonización e inmigración extranjera}

La propuesta programática de colonización del Carare contemplaba, en términos económicos, el interés de aumentar la productividad agrícola, para lo cual fue necesario según Caballero: "introducir al país colonos extranjeros bien escogidos en prácticas y técnicas agrícolas, que hayan logrado un alto nivel de responsabilidad social y económica, el cual será un instrumento de educación, más que un elemento de trabajo, y por tanto es necesario seleccionarlo cuidadosamente en su país de origen”, (Caballero Calderón, 1953).

El ICI conciente de la importancia que representaba para el país una inmigración masiva y seleccionada de personal extranjero, especializado en la explotación agropecuaria, incluyó dentro del plan de colonización el establecimiento dentro del territorio del Carare un $20 \%$ de colonos extranjeros, sobre el total de los colonos que instaló. Como plan inicial y de ensayo instaló 25 familias japonesas; con la ayuda económica y la orientación técnica del ICI, se dedicaron al cultivo y producción de arroz y demás productos de la región.

La inmigración se realizó sobre bases técnicas, con personal calificado en diferentes especialidades como la ganadería y la agricultura y tuvo como función principal difundir los conocimientos, experiencias y técnicas, entre los colonos nacionales e internacionales. Tanto los colonos colombianos que fueron la gran mayoría, como los extranjeros, estaban amparados por las mismas garantías de financiación y orientación por parte del instituto.

\section{Granja agropecuaria para colonos}

Se orientó la producción de ganado y madera en gran escala, lo registra el diario Vanguardia Liberal así: "15 mil cabezas de ganado producirá Santa Helena”. Será el centro agropecuario de mayor porvenir en Santander. "Es la región donde los pastos crecen abruptamente" "una región maderera con perspectivas insospechables para la exportación”, (Vanguardia Liberal, 1954).

Desde enero de 1954, se presentó una invasión de pobladores de diferentes zonas del país, el diario Vanguardia Liberal narra éste proceso de colonización 
en los siguientes términos: "Desde hace 5 meses ha habido una invasión de antioqueños, que han construido sus casas con tiendas y radiolas", (Vanguardia Liberal 1954). Esta publicación permite evidenciar que en el Carare a partir de la llegada de los colonos, llegaron a producir aprovechando el apoyo del gobierno del General Rojas Pinilla; también llegaron otros pobladores de la región de Antioquia a brindarles diversión y comercio de víveres, a cambio del dinero producto de su trabajo.

Los comerciantes que llegaron de diferentes orígenes, especialmente de Antioquia, fueron los grandes beneficiados con el programa para colonos en la región del Carare, pues con el producto de sus utilidades algunos lograron comprar y otros arrebatarles las tierras que les habían adjudicado a los colonos en el período 1953-1957, las cuales ya estaban dotadas de infraestructura de servicios y vías; es por ello que posteriormente son los dueños de las grandes ganaderías del departamento de Santander, generando nuevamente conflicto por la estructura de tenencia de esas tierras.

Vanguardia Liberal registra, que el ejército estableció en Cimitarra un comisariato con artículos llevados desde Bogotá, para suministrar créditos a los campesinos y trabajadores de las granjas. Igualmente, "Hay un hospital construido por el ejército, planta eléctrica y una granja con 100 reses y 400 bestias entre cría, carga y silla”.

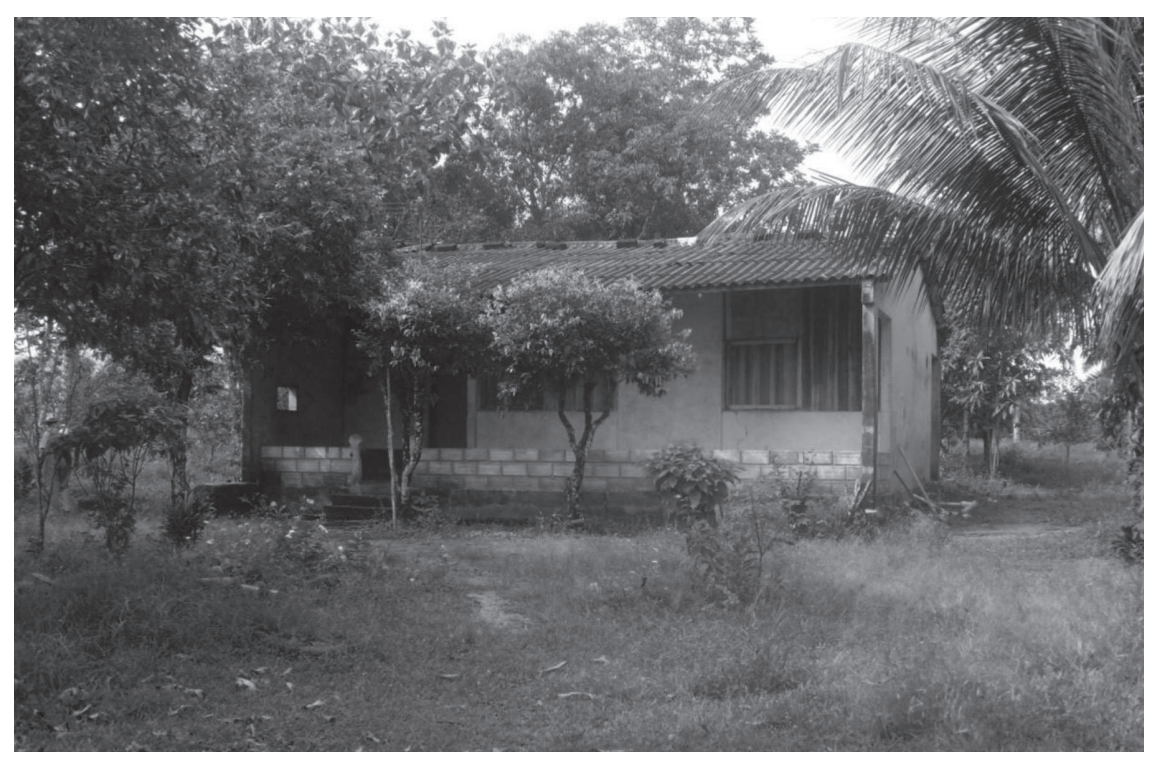

Figura 5. Cimitarra, casa construida por el INSCREDIAL en una granja para colono en 1954

Fuente: Autora, tomada el 4 de mayo de 2012. 
De igual manera, el informe al Presidente de la República de Colombia que presentó el gerente liquidador del ICI, describió la entrega de una granja agropecuaria, y 20 parcelas de 20 hectáreas cada una, con su respectiva vivienda y 10 casas prefabricadas con todos sus servicios, las cuales están destinadas para centro de recreación de colonos, (figura 5).

\section{Adjudicación de parcelas a colonos.}

El 16 de junio de 1954 en la primera página del diario Vanguardia Liberal, se publican los requisitos para adjudicación de parcelas en la zona de colonización de Cimitarra; el doctor Miguel Cuervo Araoz, gerente del ICI, envió al Comité de Atención Santandereano CAS, copia del decreto 2113 de 1948 en el cual se mencionan, (Vanguardia Liberal, 1954). El texto fue enviado el 8 de junio de 1954 al señor Roberto Harkov Valderrama, secretario del CAS de Santander ubicado en Bucaramanga, el cual establece en su Artículo 15 el siguiente orden de preferencia entre los solicitantes:

1. Quienes acrediten haber sido habitualmente agricultores, ya sea como propietarios, arrendatarios, aparceros o jornaleros.

2. A los agrónomos y demás aspirantes, que acrediten competencia a los trabajos agrícolas con certificaciones de establecimientos de enseñanza en la materia, o por haber trabajado en compañías agrícolas oficiales.

3. A quien se encuentre en el predio que vaya a parcelarse como: poseedor, aparcero, arrendatario, o cualquier otro título parecido.

4. A los que pertenezcan a la misma región o medio climático o hayan permanecido allá, al menos dos años.

5. A los padres de familia, prefiriendo a los que tengan hijos en posibilidad de trabajar.

6. Al hijo mayor del parcelero mayor de 18 años y casado.

Igualmente el Artículo 16 establece que el aspirante escogido de los cuestionarios llenados para el caso, debe anexar los siguientes documentos:

a) Una certificación de Policía Nacional sobre sus buenos antecedentes.

b) Un certificado médico que conste que él y su familia no tienen enfermedad infectocontagiosa, y que es apto físicamente para el trabajo del campo. 
c) Una certificación de Hacienda Nacional sobre las declaraciones de renta o patrimonio del aspirante, en la cual no aparezca con predios rurales o un capital mayor a $\$ 5.000$.

d) La prueba de ser mayor de 18 años y menor de 50 .

e) En cuanto a las pruebas de estado civil que acrediten los mayores de 50 , podrán ser adjudicatarios si tienen hijos menores de 17 , solteros y trabajen con ellos, viudos, solteros que sean jefes de familia y que vivan a sus expensas. "Esta comunicación la firma Álvaro Echeverri M. Secretario General del ICI", (Vanguardia Liberal, 1954).

Informaciones de fuentes autorizadas, indican que los actos programados por el ICI, en su momento, bajo la gerencia del ingeniero Miguel Cuervo Araoz, estarán presididos por el General Rojas Pinilla, quien manejando su propio helicóptero, irá de Melgar a Cimitarra. Lo acompañan el Brigadier General Charris, Ministro de Agricultura y Ministros del gabinete al igual que el gobernador de Santander, Coronel Gustavo Gómez Rodríguez, (Vanguardia Liberal 1954).

El 10 de julio del mismo año se citaba en el titular de Vanguardia Liberal: "75.000 hectáreas de baldios serán adquiridas por el departamento, para adjudicarlas a los colonos santandereanos, en la zona comprendida entre la quebrada de la Cristalina y FFCC de Puerto Wilches - Quebrada del Conde - Río Sogamoso, (Vanguardia Liberal, 1954)'”.

El titular del 23 de enero de 1955 del periódico Vanguardia Liberal, registra que: "Más de \$7 millones invertidos en la colonización de Cimitarra, en 78 parcelas, en las labores de colonización de Cimitarra y el Carare, para campamentos, edificios administrativos, cercas de industria maderera”, (Vanguardia Liberal 1955).

Otra de las labores que realizó el ICI en el Carare, fue la titulación a los colonos espontáneos de las parcelas ya establecidas y la instalación de nuevos colonos, los colonos espontáneos, eran pobladores que habían llegado a la región huyendo de la violencia bipartidista de la época, la cual se daba entre liberales y conservadores, y que dejó más de 300.000 muertos, (Molano Bravo, 2000).

En cumplimiento de un plan coordinado y técnico de beneficio de las tierras, el ICI realizó un plan de colonización dirigida y controlada que pretendía asegurar al colono un mayor rendimiento y una mejor calidad de sus productos, sin menoscabo de la calidad de sus tierras. La base económica de esa colonización, era la ganadería, complementada con los cultivos de la región y el aprovechamiento y beneficio de los bosques.

Este proceso fue proyectado por etapas así: en la primera etapa el ICI programó un plan de desarrollo a 10 años, durante los cuales pretendía adecuar y adjudicar 
55.000 hectáreas aproximadamente, distribuidas por parcelas de 50, 200 y 500 hectáreas cada una, (Molano Bravo, 2000).

Adjudicación de baldios proyecto de colonización de Carare 1953-1957

El programa de colonización en Colombia, 1953 a 1957, fue orientado a partir del decreto 1894 de 1953, el cual creó el Instituto de Colonización e Inmigración ICI, como el responsable de éste proceso. El ICI quedó autorizado para expedir los títulos de dominio de los terrenos que se adjudicaron en los baldíos reservados para la colonización, (Presidencia de la República, 1953). Los contratos que celebró el ICI con personas naturales o jurídicas nacionales o extranjeras, únicamente requerían para su validez la aprobación del presidente de la república, esto con base en el artículo 18 del decreto mencionado.

Igualmente, el presidente de la República a través de la división de Recursos Naturales, Sección Baldíos, del Ministerio de Agricultura, le otorgó los títulos de baldíos al ICI: "Aproximadamente 800.000 hectáreas, ubicadas a lo largo del trazado del ferrocarril del Río Magdalena, en los municipios de Vélez y Bolivar", (Ministerio de Agricultura, 1953), con el propósito de que fueran asignados posteriormente a los colonos, a partir de créditos cómodos, que concedía la Caja de Crédito Agrario, el Banco Popular Colonial, el Fondo de Fomento Ganadero y el mismo ICI.

Para el caso del Carare, cabe resaltar como ejemplo de éste proceso de asignación de baldíos, la reserva que hizo el Ministerio de Agricultura a favor del Instituto, mediante el Decreto 2547 de 1953, en la cual se otorgó:

“...Una extensión aproximada de 189.260 hectáreas, comprendida dentro de los siguientes linderos, por el norte, desde la desembocadura del Horta en el Carare aguas arriba del Horta, hasta la confluencia del río Blanco, en línea recta en una extensión de $27 \mathrm{~km}$. Hasta la confluencia de la quebrada la Pedregosa con el río Minero, de éste punto en línea recta en una distancia aproximada de $16 \mathrm{~km}$. Hasta el punto denominado Guinel, situado sobre el río Ermitaño, siguiendo éste río aguas abajo por la banda izquierda, hasta Puerto Olaya, de Puerto Olaya sigue la carretera del Carare, Hasta Puerto Araujo sobre el río Carare; río Carare arriba, hasta la confluencia con el río Horta punto de partida", (Presidencia de la República, 1953).

Por otro lado, en la misma fecha la Junta directiva del Comité de Atención Santandereano CAS, solicitó a través de Marconi, al señor gerente del ICI, Cuervo Araoz, intervenir para que los santandereanos desvinculados de esa importante colonización fueran favorecidos con adjudicación de parcela, (Vanguardia Liberal, 1954). Esta petición la realizaron, ya que se estaba colonizando tierra santandereana, sin tener en cuenta a los coterráneos del 
departamento, puesto que los colonos procedían de otras zonas del país, como se mencionó anteriormente.

El Gobernador del Departamento de Santander, hace un reconocimiento al presidente honorario del CAS, por su sinceridad patriótica y de lucha por la inclusión de los santandereanos al proyecto de colonización del Carare, afirmando que los santandereanos están dispuestos a viajar a la zona de Cimitarra. Narra el periódico Vanguardia Liberal el siguiente comentario, del señor gobernador:

"En la mañana del lunes 7 de junio de 1954, me visitó el señor Carlos Vanegas, natural de Girón y campesino de profesión, quien junto con otros 12 campesinos, están dispuestos a viajar al frente de colonización de Cimitarra, solicitando que el gobierno los ayude en el traslado, ya que cumplen los requisitos para que les adjudiquen tierras para la agricultura. Los campesinos de Girón, son los primeros campesinos santandereanos que solicitan la inclusión en el programa de colonización que se adelanta en su departamento, 12 es una cifra mínima respecto a los 400 obreros-colonos que para entonces se encontraban trabajando como aserradores en la zona a órdenes del ICI", (Vanguardia Liberal, 1954).

Tercera estrategia de desarrollo económico en el Carare: industrialización.

En aras de fortalecer el sector industrial a partir de la inversión, tanto pública como privada, el General Rojas Pinilla, planteó la tercera estrategia de desarrollo económico en el período de su gobierno 1953-1957, la cual establecía acciones muy concretas para el Carare; el ICI orientó una política de apoyo y fomento a la industria y como representante de la institucionalidad colombiana, para el fortalecimiento de las regiones colonizadas, fue el mayor accionista de la empresa Láminas de Fibra del Carare S.A., dedicada a la explotación maderera en gran escala, cuyos productos fueron la madera aserrada y láminas de fibra prensada. La empresa pretendía garantizar un mercado fijo para las maderas que explotaran los colonos en la adecuación de sus parcelas.

\section{Conclusiones}

1. Las trasformaciones del paisaje rural colombiano en el siglo XX, fueron en gran parte el resultado de migraciones desde los núcleos poblacionales andinos, hacia las tierras de vertiente de las fronteras. Espontáneos unos y dirigidos otros, ambos movimientos contribuyeron a la consolidación de nuevos territorios y a la incorporación de tierras baldías a la economía regional y nacional.

2. La colonización espontánea se da como consecuencia de las imprevisiones del gobierno, quien a pesar de intentar apoyar las 
aspiraciones de los colonos para tener un pedazo de tierra, vía reforma agraria y/o regulación que ampare la posesión de la misma durante un periodo de tiempo, hasta ahora no se ha logrado.

3. En el periodo estudiado, 1953-1957, la colonización dirigida se enmarcó como una política pública planificada que buscaba "fomentar el progreso económico y social de las partes menos desarrolladas del país, a través de centros de colonización y de una política de estímulo a la inmigración", para beneficiar a colonos desplazados por la violencia y mejorar su condición de vida.

4. La colonización dirigida empresarial, orientada por el General Gustavo Rojas Pinilla, incluyó tres estrategias de desarrollo económico a saber: infraestructura, Colonización e Industrialización

5. La primera estrategia de desarrollo económico del periodo de gobierno 1953-1957, orientó para la región del Carare apoyo a colonos en dotación de infraestructura productiva a través de la construcción de vías y aeródromo que les permitiera vincular la región a la economía nacional e internacional.

6. La segunda estrategia de desarrollo económico fue la colonización, la cual orientó para los colonos ubicados en el Carare dotación de granjas, titulación de baldíos, créditos y capacitación en producción por parte de colonos inmigrantes a su vez capacitados en producción apta para las condiciones de suelos y clima entre otros aspectos; igualmente, dotó la región de infraestructura que contribuyó a la reproducción social de la población, tal como: construcción de puesto de higiene, escuelas y viviendas; todo esto contribuyó a generar las condiciones para incrementar la población.

7. La tercera estrategia de desarrollo económico del gobierno del general Gustavo Rojas Pinilla, fue la Industrialización; es por ello que el Instituto de Colonización e Inmigración, fue el mayor accionista de la empresa Láminas de Fibra del Carare S.A., dedicada a la explotación maderera en gran escala, cuyos productos fueron la madera aserrada y láminas de fibra prensada, la empresa pretendía garantizar un mercado fijo para las maderas que explotaran los colonos en la adecuación de sus parcelas y de ésta manera garantizar empleo e ingresos a los colonos, los cuales contribuirían en el ciclo económico a generar demanda agregada y por supuesto más inversión y crecimiento económico en la región.

8. El crecimiento económico generado, acompañado de dotación de infraestructura reproductiva en salud, educación y vivienda, contribuyó igualmente a desarrollar la región y incrementar la población, lo cual generó las condiciones para que en las dos décadas siguientes a 
la colonización del Carare, se crearan municipios como Cimitarra, Landázuri, Puerto Parra y Santa Helena del Opón, como resultado del programa colonizador del general Gustavo Rojas Pinilla en su periodo de gobierno 1953-1957.

\section{Referencias bibliográficas}

Artunduaga, Gustavo. "La reforma agraria y las transformaciones de la agricultura en Colombia y Venezuela.» Estudios Latinoamericanos, $n^{\circ} 4$ (1978): 181-242.

Caballero Calderón, Eduardo. «Inmigración y Colonización.» El Tiempo, 31 de julio de 1953 .

Currie, Lauchlin. La agricultura colombiana en el siglo 20. Editado por Mario Arrubla. Bogotá: Editorial Andes, 1976.

Espinosa Valderrama, Augusto. Vanguardia Liberal, 4 de junio de 1954.

Fajardo, Dario. La colonización de la Macarena en la História de la frontera agraria. Editado por Banco de la Republica. 15 de 6 de 2012. http://www.blaa.gov.co (último acceso: 15 de 6 de 2012).

INCORA. Reforma Agraria Colombiana, informe de actividades. Editado por FAO. Bogotá D. E.: XII Conferencia Regonal de la FAO para América Latina, 1972.

Instituto Geográfico Agustín Codazzi IGAC. Atlas de Colombia. Cuarta Ed. Editado por Iván Dario Gómez Guzman. Bogotá: Instituto Geográfico Agustín Codazzi IGAC, 1992.

Johnston, Bruce. Agricultura y transformación estructural. México: Fondo de Cultura Económica, 1980.

LeGrand, Katherine. Colonización y protesta campesina 1850 - 1950. Bogotá: Universidad Nacional de Colombia, 1989.

Meertens, Donny. Mujer y colonización en el Guaviare. Bogotá: Colombia Amazónica, 1998.

Ministerio de Agricultura. Resolución $N^{\circ} 220$ del 25 de septiembre de 1953. Resolución, Bogotá: Ministerio de Agricultura, 1953.

Molano Bravo, Alfredo. El plan Colombia y el conflicto. Interpretado por Comisión de Cooperación al Desarrollo. Parlamento Europeo, Brucelas. 12 de septiembre de 2000.

ONU. Progress in land reform, second report. New York: ONU, 1956. 
Presidencia de la Republica. «Decreto 0870.» Decreto 0870 del 26 de marzo de 1953. Bogotá: PRESIDENCIA DE LA REPUBLICA, 26 de Marzo de 1953.

Presidencia de la República. «Decreto 1984 de julio 18 de 1953.» Diario Oficial. Bogotá: Presidencia, 18 de julio de 1953.

—. «Decreto 2547, de septiembre 30 de 1953.» Diario Oficial, 30 de septiembre de 1953.

—. «Decreto $N^{\circ} 1894$ de 1953.» Diario Oficial, 1953.

Revista de Economía Colombiana. «Informe especial de economía colombiana.» Revista de Economía Colombiana, 1954: 278.

Vanguardia Liberal. «15 MIL CABEZAS DE GANADO PRODUCIRÁ SANTA HELENA.» Vanguardia Liberal, 10 de mayo de 1954.

—. «5 millones de pesos con destino a crédito para colonos.» Vanguardía Liberal, 26 de marzo de 1955 .

—. «Marconi a Cuervo Araoz.» Vanguardia Liberal, 4 de junio de 1954.

-. «Requisitos para adjudicación de parcelas en la zona de colonización de Cimitarra.» Vanguardia Liberal, 16 de junio de 1954.

—. «Reunión extraordinaria del Comité de Acción Santandereano .» Vanguardia Liberal, 2 de junio de 1954.

—. «Situación actual de las fértiles tierras del Carare.» Vanguardia Liberal, 12 de mayo de 1954.

—. «Vanguardia Liberal.» Vanguardia Liberal, 14 de marzo de 1954.

—. «Vanguardia Liberal.» Vanguardia Liberal, 20 de junio de 1954.

—. «Vanguardia Liberal.» Vanguardia Liberal, 10 de julio de 1954.

—. «Vanguardia Liberal.» Vanguardia Liberal, 23 de enero de 1955. 